\title{
Observations on Euglena deses.
}

ROSE BRACHER.

With nine Figures in the Text.

Contents.

Section I I I

" III. Behaviour of E. DESES When removed from the Influence of the

TIDE • • • • • • • • • • • • • • 99

" IV. Further Investigations of the Influence of Light and Temperature on the Behaviour of E. DESES • • • • • • • • IO०

" V. Depth to which E. DESES burrows in Mud . . . . . . 104

" Vi. Climatic Conditions • • • • • • • • • • • Io5

" VII. The NeEd For OXYgen • • • . • . • . • • • IO6

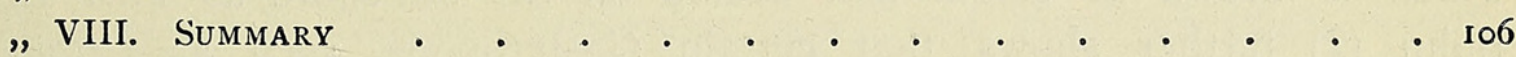

" IX. Conclusion • • • • • • • • • • • • • • • • • IO7

BIBLIOGRAPHY . . . . . . . . . . . . . . . . 108

\section{INTRODUCTION.}

$7 \mathrm{HE}$ organism with which this paper has to deal occurs along the banks 1 of the river Avon within its tidal portion, which extends for about seven and a half miles inland. The actual point at which the present work was for the most part carried out is about a quarter of a mile lower down the river than the Clifton Suspension Bridge. At low tide the river in this part of its course is reduced to a very narrow stream, leaving exposed on either side wide stretches of mud.

On examining the surface of the mud, one can see that parts are coloured bright green, while in other places the mud appears yellowish brown in hue. Closer examination reveals the fact that the green colour is restricted to small patches varying from a quarter of an inch to one inch in diameter, and often so close together as to form an almost continuous carpet.

[Annals of Botany, Vol, XXXIIJ. No. CXXIX. January, 1919.] 
By examining small quantities of the mud under the microscope, one can see that the green colour is due to the presence of a vast number of small green organisms, identified by the aid of Dangeard (3) and Wager (7) to be Euglena deses. The yellow and brown colour is due to the presence of a large number of diatoms, and it is a noteworthy fact that while the Euglenae occupy, for the most part, the higher positions on the ridges of mud, the diatoms are usually to be found in the damper mud of the hollows.

According to Dangeard (4) Euglena requires a certain amount of organic matter for its nutrition, and the occurrence of the organism in so great abundance here is probably due to the quantity of sewage brought down to the Avon from the neighbouring towns. An analysis of the mud at this spot shows that the organic content is 6 per cent. (approx.).

By continuing observations on the banks of the Avon, one may see that the green colour mentioned above is not permanently on the mud, but disappears and reappears apparently according to the times of sunrise, sunset, and high tide. One may well compare the behaviour of this organism with that of Convoluta roscoffensis described by Gamble and Keeble (5) and Georges Bohn (1). This animal is found on the shores of Brittany, where it colours patches of the sand bright green. It comes to the surface during certain times of the day, but burrows into the sand during darkness and for the periods of high tide. Laurie (6) describes similar diurnal movements in the Peridinian, Amphidinium operculatum, which is brown in colour and occurs on the sea-shore at Port Erin. Bohn (2) further shows that certain Gasteropods, such as Littorina rudis, exhibit diurnal migrations, taking shelter under pebbles and rocks during darkness and high-tide periods.

Although such comparisons are of great interest, one should remember that in all the organisms mentioned above, with the exception of the Peridinian, there is a much more highly developed structure than in the unicellular Euglena, and therefore it is not wise to lay too great a stress on their similarities and differences.

This paper was, therefore, undertaken with a view to investigating the possible influence of such external factors as light, tidal flow, and temperature changes upon the movements of $E$. deses and the part which they play in the life of the organisms.

$E$. deses is very contractile and constantly changing its shape. By a series of changes, consisting chiefly of contraction into a ball, expansion to full length, and bending round upon itself, the organism is able to creep about over the surface of the mud. $U p$ to the present time no cilia have been observed, and in the experiments performed the organism appears to be unable to swim freely in water. One would expect, therefore, that any response to stimuli which the organism makes would of necessity be much 
slower than that made by the free-swimming forms such as E. viridis. Fig. I shows the changes in shape occurring in one specimen of $E$. deses during several minutes' observation under the microscope.

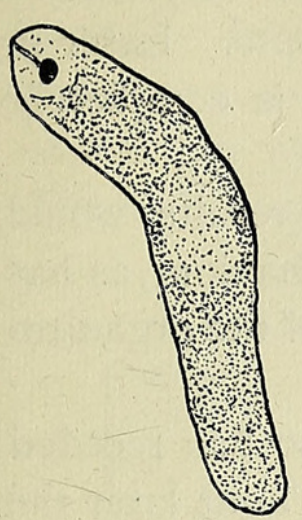

I

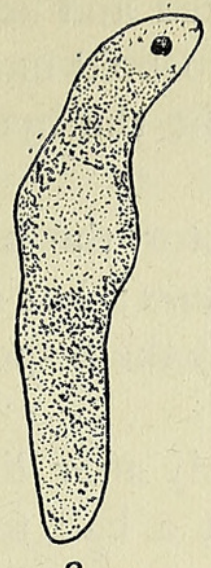

2
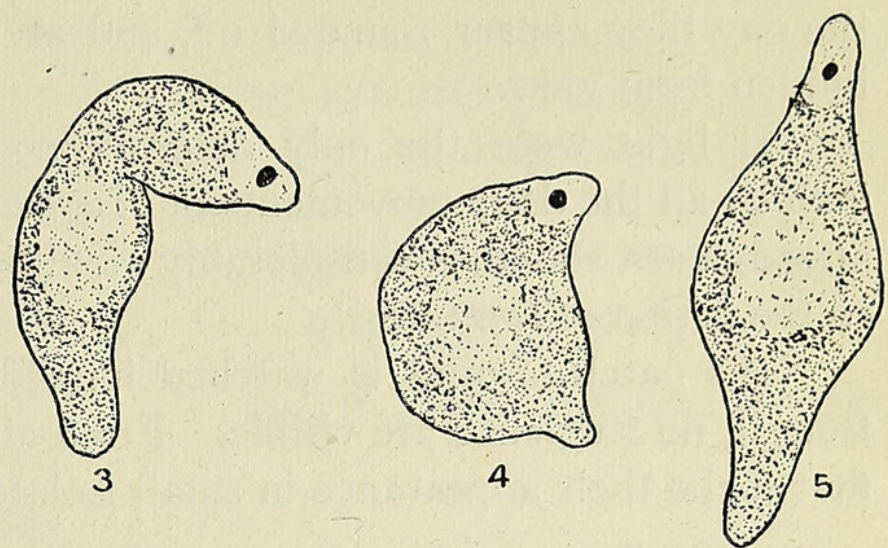

FIG. I. I-5. Euglena deses, showing changes in shape occurring in one individual during several minutes' observation. (Mag. 400 times.)

\section{DAILY Movements of E. DESES DEPENDENT ON EXTternal}

\section{FACTORS.}

A series of observations were made on the Avon banks between dawn and sunset with a view to investigating the times of the daily movements of Euglena.

At dawn no Euglenae are visible on the surface of the mud, but from readings taken in October, December, April, and May the green colour begins to appear about one to two hours after sunrise.

$\begin{array}{llcc}\text { Month. } & \text { Week. } & \begin{array}{c}\text { Average } \\ \text { Time of } \\ \text { Sunrise }\end{array} & \begin{array}{c}\text { Time of } \\ \text { Appearance } \\ \text { of Euglenae. }\end{array} \\ \text { October } & \text { 8th-15th } & 6.12 & 7.30 \\ \text { December } & 3^{\text {rd- }} \text { th } & 7.45 & 9.0 \\ \text { April } & 23^{\text {rd-2gth }} & 4.37 & 6.30 \\ \text { May } & \text { 14th-2oth }^{\text {th }} & 4.3 & 6.0\end{array}$

As the light becomes brighter and the temperature increases the mud becomes correspondingly greener, until about midday the surface is very green indeed. The organisms remain thus exposed until the light begins to fade in the evening, when they once more disappear from view and burrow down into the mud. Readings were taken in the same months for the time of disappearance of the organism, which is shown to be less than half an hour before sunset.

$\begin{array}{llcc}\text { Month. } & \text { Week. } & \begin{array}{c}\text { Average } \\ \text { Time of } \\ \text { Sunset. }\end{array} & \begin{array}{c}\text { Time of } \\ \text { Disappearance. }\end{array} \\ \text { October } & \text { 8th-15th } & 5 \cdot 15 & 5.0 \\ \text { December } & 3^{\text {rd-9th }} & 3.49 & 3.30 \\ \text { April } & 23 \text { rd-29th } & 7.18 & 7.0 \\ \text { May } & 14^{\text {th-20th }} & 7.40 & 7.30\end{array}$


The diurnal movements would cause one to expect corresponding changes in the appearance of the organism during the day, and accordingly drawings were made at various times to investigate the nature of these.

Early in the morning they appear extended and active as they rise to the surface and are moving with continual amoeboid movements. Later in the day they appear rounded off, and at night the eyespot is completely hidden from view.

If light were the only determining factor the above results would include all the daily movements of Euglena deses; but its behaviour, as has already been stated, is considerably modified by the response of the organism to the action of the tide.

If a patch of mud is watched immediately after the tide has receded from it, no Euglenae are visible. From about a half to one hour later the first make their appearance in small isolated groups, about a quarter of an
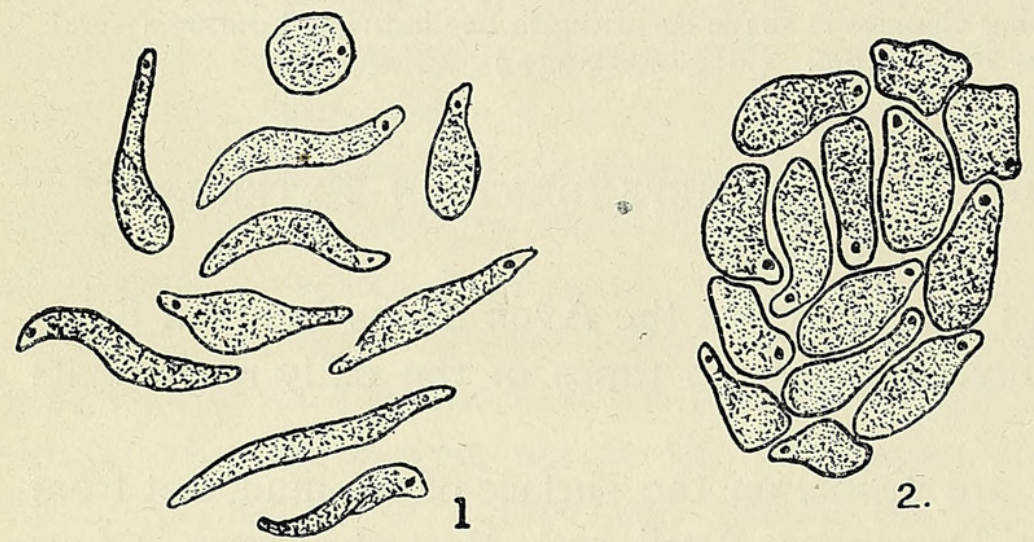

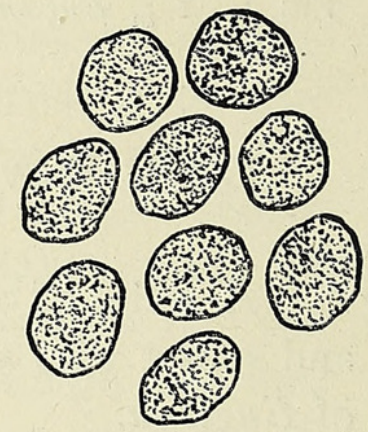

3.

FIG. 2. E. deses. Diurnal differences in appearance. (Mag. Ioo times.) (I) Early morning (actively moving); (2) midday (lying still on mud surface); (3) night (rounded off).

inch in diameter. With regard to the incoming tide, the Euglenae do not disappear into the mud before they are covered by the tide, but when a few ripples of the rising water have passed over the spot they burrow down, and the green colour quickly fades and does not reappear until after the water has gone back.

It may be seen, therefore, that the intervention of the action of the tide alters to a considerable extent the simple diurnal movements dependent solely upon light, and one would expect to find much variation in the behaviour of the organism according as the two factors, light and tidal action, are reacting simultaneously or at different times.

In order to keep the Euglenae under closer observation and yet under natural conditions, an apparatus was devised for producing a periodic tidal flow over a given area of mud. In main essentials this apparatus consisted of a tank which was filled and emptied automatically by means of siphons which had been so arranged as to produce a tide at the proper time. In Fig. 3 a drawing of the apparatus is shown. 
Mud (M) is placed in the glass tank $\mathrm{T}$ in the position shown in diagram. Cement dams $\left(C_{1}\right.$ and $\left.C_{2}\right)$ serve to keep the mud in position. Water is stored in two vessels $\left(A_{1}\right.$ and $\left.A_{2}\right)$ which are connected by the siphon $S_{1}$. By means of a tap at the base of the siphon $S_{2}$ water is run drop by drop into the bottle B. By keeping this always overflowing, the pressure of water in the bottle remains approximately constant. By means of the tap water from the bottle is then run into the inverted bell-jar J. The indicator I enables the stop-cock to be kept at a definite angle, and
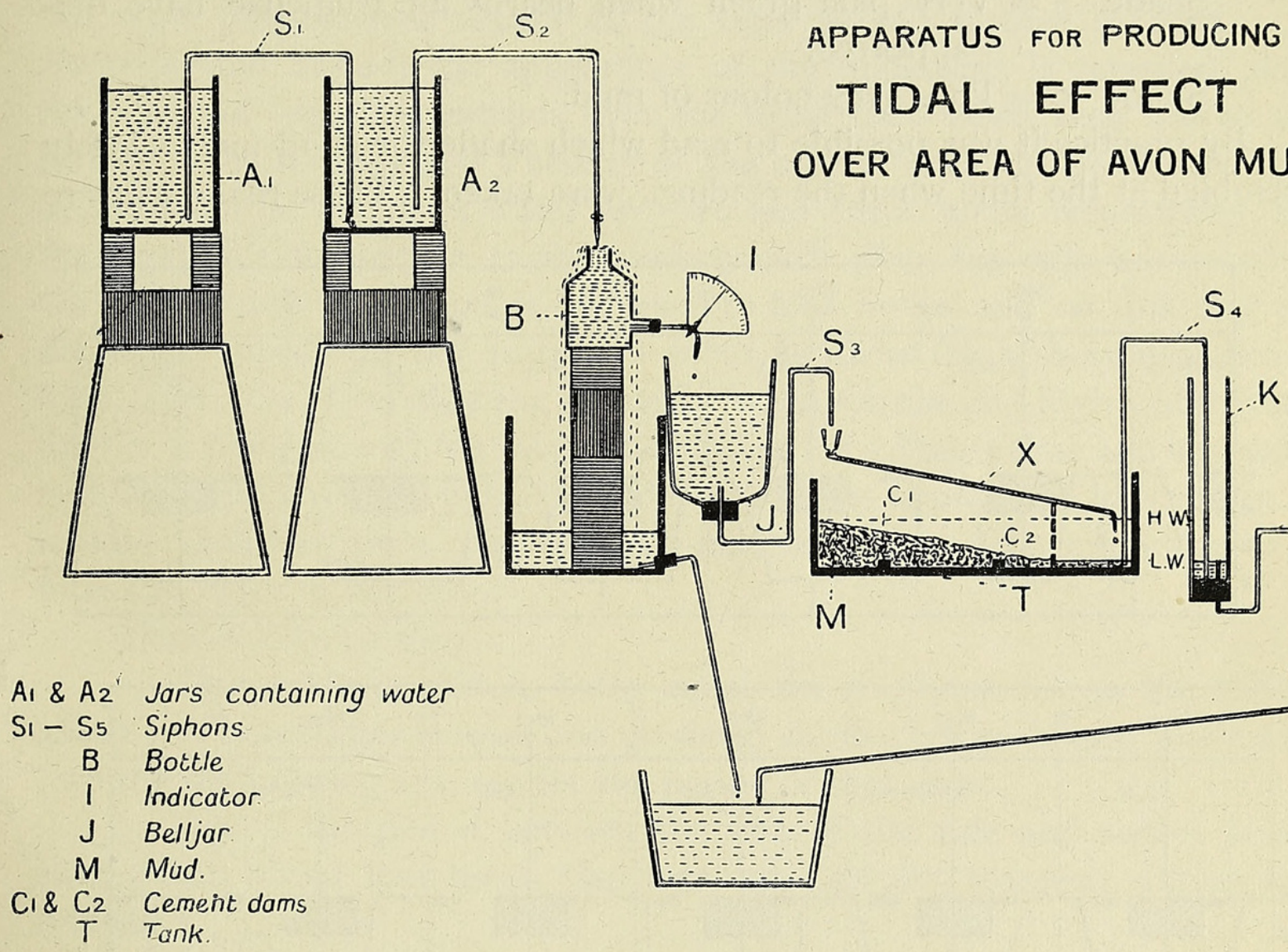

\section{OVER AREA OF AVON MUD}

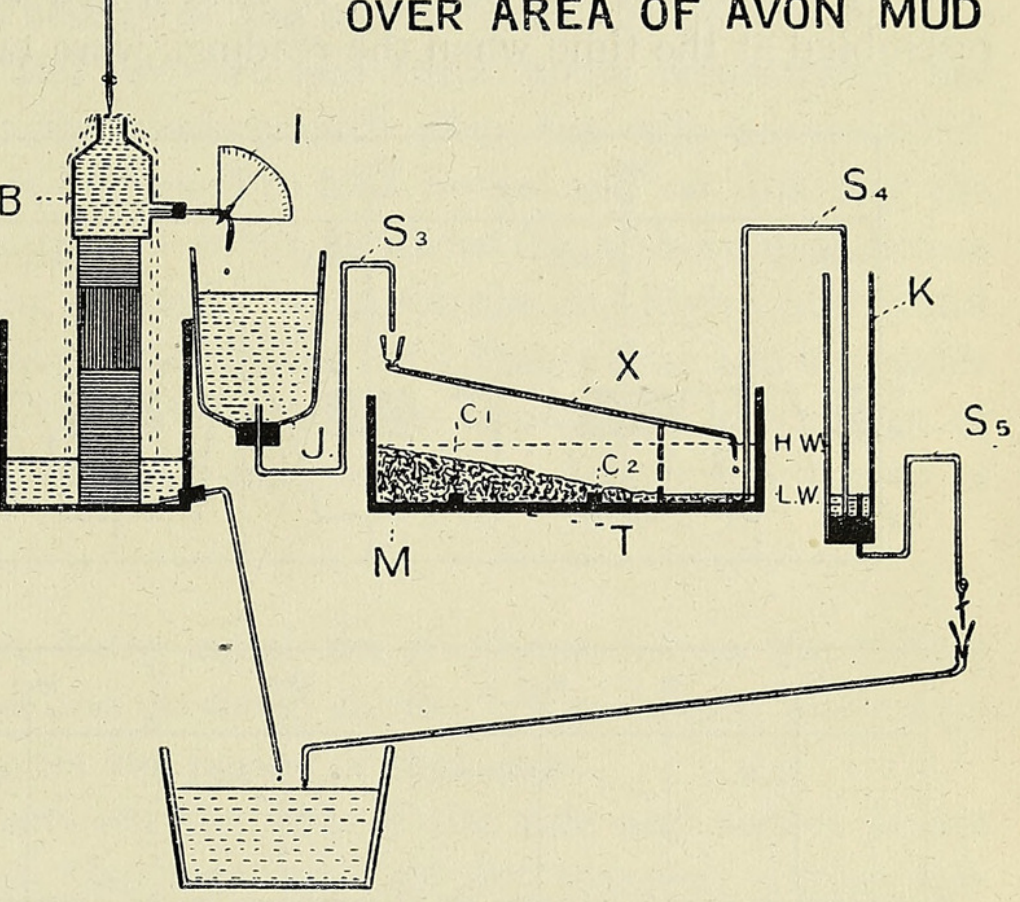

FIG. 3 .

by adjusting this the time taken to fill the bell-jar may be regulated. By trial it was possible to fill the bell-jar to the required level in twelve hours. In reaching the level of the siphon $S_{3}$ the water all passes over into the tank by means of the tube $\mathrm{x}$, and high tide is effected. The outgoing tide is arranged thus: As the water rises in the tank $\mathrm{T}$ it also rises in the glass cylinder $\mathrm{K}$, the two being connected by the siphon $\mathrm{S}_{4}$. This cylinder is too narrow to allow any appreciable fall of water to take place in the tank. On reaching the level of the siphon $S_{5}$ the water in the cylinder is gradually passed off by means of slow dripping from the tap at the end of the siphon, and accordingly the water is gradually emptied from the tank until it reaches the level of the upper end of siphon $S_{5}$ within the cylinder, when air enters and the flow of water is stopped. By 
regulating the tap the duration of high tide may be altered to suit the experiment.

As the greenness of the mud varied from hour to hour, readings were taken, and for this purpose a colour scale was made consisting of four colours to which the numbers $0,5,10$, and 15 were given respectively.

Shade $15=$ Brightest green colour on mud.

Shade $\mathrm{IO}=$ Green colour shown when Euglenae are beginning to go down.

Shade $5=$ Very pale green when nearly all Euglenae have disappeared.

Shade $0=$ Pure grey colour of mud.

By practice it was possible to read which shade the mud most closely resembled at the time when the readings were taken. These readings were
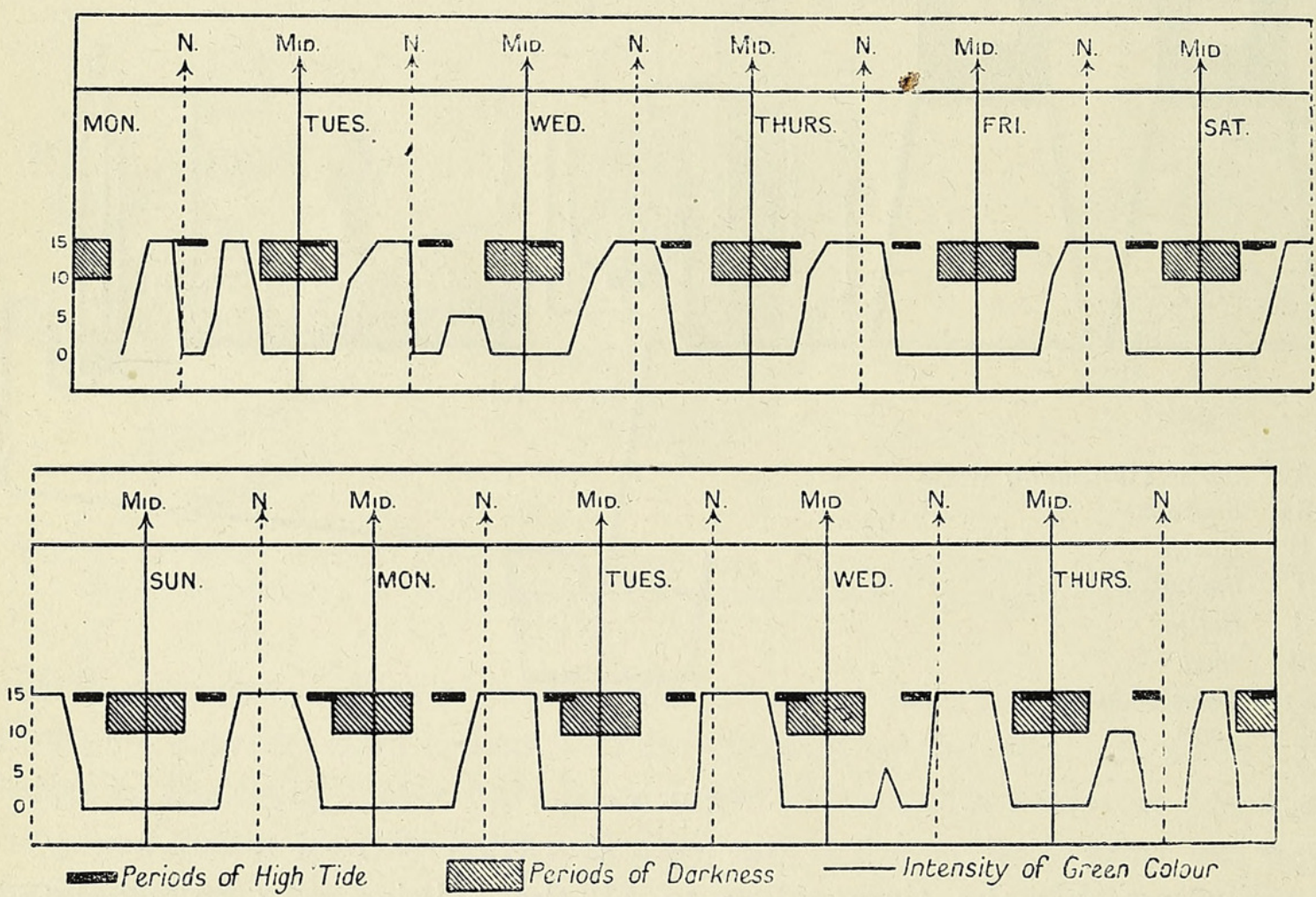

FIG. 4. The graph represents the intensity of greenness on the mud under normal conditions with reference to the periods of high water (depicted black) and of darkness (depicted shaded). The intensity of greenness is measured according to the following scale: I 5 (bright green), Io (green), 5 (pale green), and o (pure grey colour of mud). The observation extends over eleven days, the divisions of which are marked at noon (N.) and midnight (Mid.).

plotted on a graph and a curve obtained, while the periods of high tide, and also those of day and night, are shown in order to compare the appearance of the mud with these (Fig. 4).

Starting on Monday it may be seen that the organisms make their appearance about two hours after sunrise and attain their maximum number on the surface between the hours of 8 a.m. and II.30 a.m. About half an hour before the tide comes in they begin to go down and completely disappear 
as the water rises over them. About half an hour after the tide has receded they reappear, regain their maximum number between the hours of three and five, and disappear again completely just before sunset. On Tuesday the process was repeated, but owing to a decrease in time (about five hours) between the ebb of the tide and the sunset, the Euglenae do not reappear to their fullest extent and the mud does not become very green. On Wednesday this period of time is reduced to four hours, and the Euglenae make no reappearance after high tide during that day. On Thursday and Friday the same phenomenon occurs as the time is still further reduced. On Saturday and Sunday the appearance of the organisms is retarded, since the period of high tide extends over the usual time when they rise to the surface. On Monday and Tuesday of the second week the periods of time between sunrise and high-water are two and three hours respectively, but the organisms do not rise to the surface until after the tide has receded. On Wednesday the period is increased to four hours, and on this day the Euglenae appear on the surface in small numbers for a short time before high tide. On Thursday the period between sunrise and high water is still further prolonged, and the Euglenae appear for a longer time and in greater numbers, but it is not until the tide once more approaches the region of midday that the green colour on the mud attains its maximum degree of intensity twice in one day.

Thus it may be seen:

I. That, other conditions being equal, the Euglenae rise to the surface about two hours after sunrise and go down shortly before sunset, burrowing into the mud during the day for the period of high tide.

2. That if the period between the ebb of the tide and sunset is not longer than about four hours, the organisms do not reappear during this interval.

3. That if the period between sunrise and high water is not longer than three hours, the organism does not appear on the surface until the tide has receded.

\section{BEHAVIOUR OF E. DESES WHEN REMOVED FROM THE INFLUENCE OF THE TIDE.}

It may easily be seen that those Euglenae which live close to the outer edge of the river bank are only covered by the tide for comparatively short periods, while those lower down may remain covered with water for several hours. Moreover, owing to the fortnightly variations in the tide, it happens that during neap tides this outer zone may be exposed for several days without being covered by the tide. Material was taken from this region and kept in dishes, and it was noticed that the organisms responded only to the stimulus of light. In other material, however, which was taken from 
a zone always under tidal influence, it was noticed that, although removed from the Avon and placed in a dish in the laboratory, the organisms still continued to burrow into the mud at the time of high tide.

In order to ascertain exactly how long this phenomenon persisted, accurate readings were taken at every hour by means of the colour scale used in the previous experiment, and curves drawn in order to show the behaviour of the organisms when removed from the influence of the tide (Fig. 5).

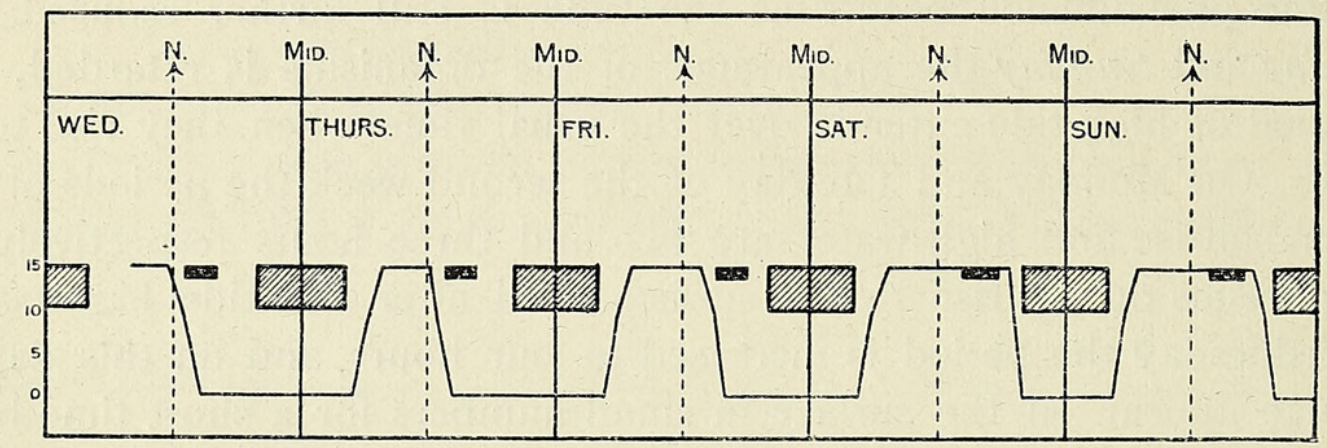

Fig. 5. A graph drawn to illustrate the behaviour of $E$. deses when removed from the influence of the tide. The lettering and shading are as in Fig. 4.

The material was obtained at 9 a.m. on Wednesday morning, when the mud was well covered with Euglenae. It was placed in the laboratory and left without any tidal influence.

\section{Result.}

On Wednesday afternoon the organisms went down during the period of high tide.

On Thursday afternoon the organisms again went down at about the same time as the period of high tide on Wednesday.

On Friday the organisms again went down for the same period, though they commenced to do so about an hour later, the disappearance being more rapid.

On Saturday and Sunday, however, the Euglenae did not disappear at all during the day until just before sunset.

Therefore, although removed from tidal influence, $E$. deses continues to show tidal periodicity for about three days. Gamble and Keeble (5) describe a similar periodicity in Convoluta, which they maintain only lasts for one day. Bohn (1), however, states that he has watched the phenomenon during fourteen consecutive tides.

Further Investigations of the Influence of Light and Temperature on the Behaviour of E. DEsES.

The influence of light. It has been shown that $E$. deses is sensitive to light, since it comes to the surface of the mud as soon as the daylight has reached a sufficient degree of intensity. Small variations in the light during 
the day appear to make no difference to the number of Euglenae on the surface, as in bright sunlight or good daylight without sun the greenness of the mud remains the same. If, however, the day is extremely dull and the intensity of the light does not reach a certain point required by the Euglenae, only a very few organisms appear, and from December ${ }_{3} 3$ to December I $_{5}$, when a very heavy fog enveloped the city, no individuals could be seen on any of the mud under observation. The Euglenae disappear into the mud at nightfall, but the same phenomenon can be brought about by placing them at any time in the dark. It was found that the time taken for complete disappearance varied with the temperature, as will be shown later, but averaged about thirty minutes. On replacing in the light the Euglenae took about the same time to rise to the surface again.

If kept in the dark for one or two days the Euglenae do not appear on the surface until replaced in daylight. If kept for longer periods a few may be visible on the surface of the mud, and eventually most of them return to the surface, probably to obtain more oxygen. The chief difference in the appearance of these Euglenae kept in the dark is the disappearance of the paramylon grains which are used as reserve food, and when all has been used up the organism dies. On being replaced in light, however, before all the paramylon has disappeared, the Euglena is able to manufacture fresh grains in a very short period of time.

Another experiment was performed in which the Euglenae were placed in dishes and illuminated only from one side in order to see if they would move towards the light.

Four dishes were used which contained respectively:

(1) A quantity of stiff mud containing Euglenae.

(2) A quantity of wet mud containing Euglenae.

(3) A quantity of mud with Euglenae, over which a layer of water half an inch deep was placed.

(4) A number of Euglenae in water only.

In (I) and (2) the Euglenae gradually moved towards the source of light, and about the end of five days were all massed at the lighter end of the dish, many heaped upon the glass.

In (3) the Euglenae moved somewhat towards the source of light, but not so pronouncedly as in (1) and (2).

In (4) the organisms kept their original position, and at the end of the day appeared completely dead, owing to a lack of oxygen and food material, as they are not able to swim in water.

In the diagram given below (Fig. 6) the positions of the Euglenae at the beginning and end of the experiment are shown.

From these experiments it may be concluded that Euglena deses is sensitive to light and moves towards the source of light, and is not repulsed by bright sunshine. 
Its movements in response to the stimulus are very slow as compared with results obtained by Wager (8) on Euglena viridis. He mentions that if a cloud passes over the sun these organisms immediately leave the position which they occupy on the surface of a pond and swim down into the water, to reappear as soon as the cloud has passed. Also a number

I.

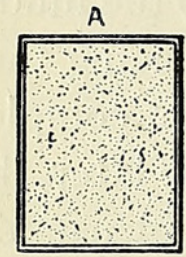

A

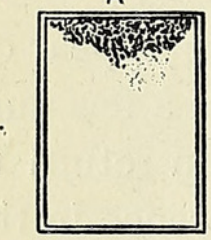

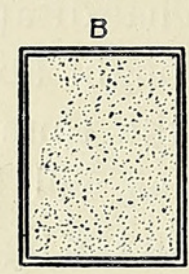

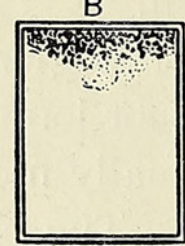

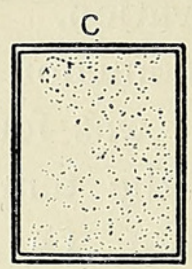

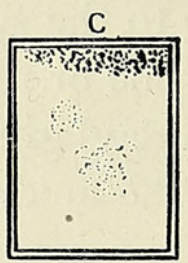

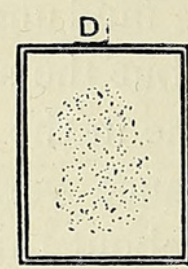

D

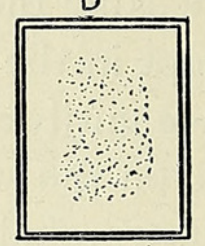

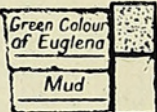

FIG. 6. (1) Position of Euglenae at commencement of experiment: A, stiff mud; B, wet mud; C, mud covered by water; D, water only. (2) Position of Euglenae after five days' illumination from one side.

of Euglenae in a saucer illuminated from one side will pass towards the source of light in a few minutes.

Influence of temperature. Cultures of Euglena were kept at temperatures ranging from $3^{\circ} \mathrm{C}$. to $20^{\circ} \mathrm{C}$, and in these the organisms appeared to flourish equally well. By changing the temperature, however, one is able to observe a marked difference in the rate at which the organism responds to stimuli.

At low temperatures, i. e. below $4{ }^{\circ} \mathrm{C}$., it was found that the Euglenae became rounded off, very sluggish, and slow in response to stimuli, but as the mud was gradually warmed up, they became more active and expanded to their fullest length.

During the winter of $1916-17$ the periods of frost were very severe. From December 6 to December 17 the average minimum temperature was $-3^{\circ} \mathrm{C}$. The mud in the vessels was frozen each night, but during the warmest part of the day, when the mud thawed and rose to a temperature of $3^{\circ} \mathrm{C}$., Euglenae were visible in small numbers for a few hours.

From January 20 onwards the mud was completely frozen for a period of twenty-nine days. The temperature frequently fell as low as $-10^{\circ} \mathrm{C}$, and the mud did not thaw at all during the day-time. When the thaw did set in, however, the mud was closely watched for any traces of Euglenae either in the vegetative or encysted form. Five days later, a faint green colour on the mud showed, on examination, that some of the Euglenae had withstood the severe frost. 
Experiments were then performed in order to see at what temperature the Euglenae become active again after freezing. Four dishes containing mud and Euglenae were placed out of doors at nightfall so that the next morning the mud in all the dishes was frozen. They were placed in a good light and kept at different temperatures as follows :

(I) Kept all day at $0^{\circ} \mathrm{C}$.

(3)

$\mathrm{I}^{\circ} \mathrm{C}$.

(4) Warmed slowly from $0^{\circ} \mathrm{C}$. to $4^{\circ} \mathrm{C}$.

These experiments were repeated several times and the following results obtained :

In (I), (2), and (3) no Euglenae appeared during the day.

In (4) the first traces of Euglenae appeared on the surface of the mud when the temperature was approximately $2 \cdot 5^{\circ} \mathrm{C}$.

If the mud is frozen while the organisms are visible and then placed in
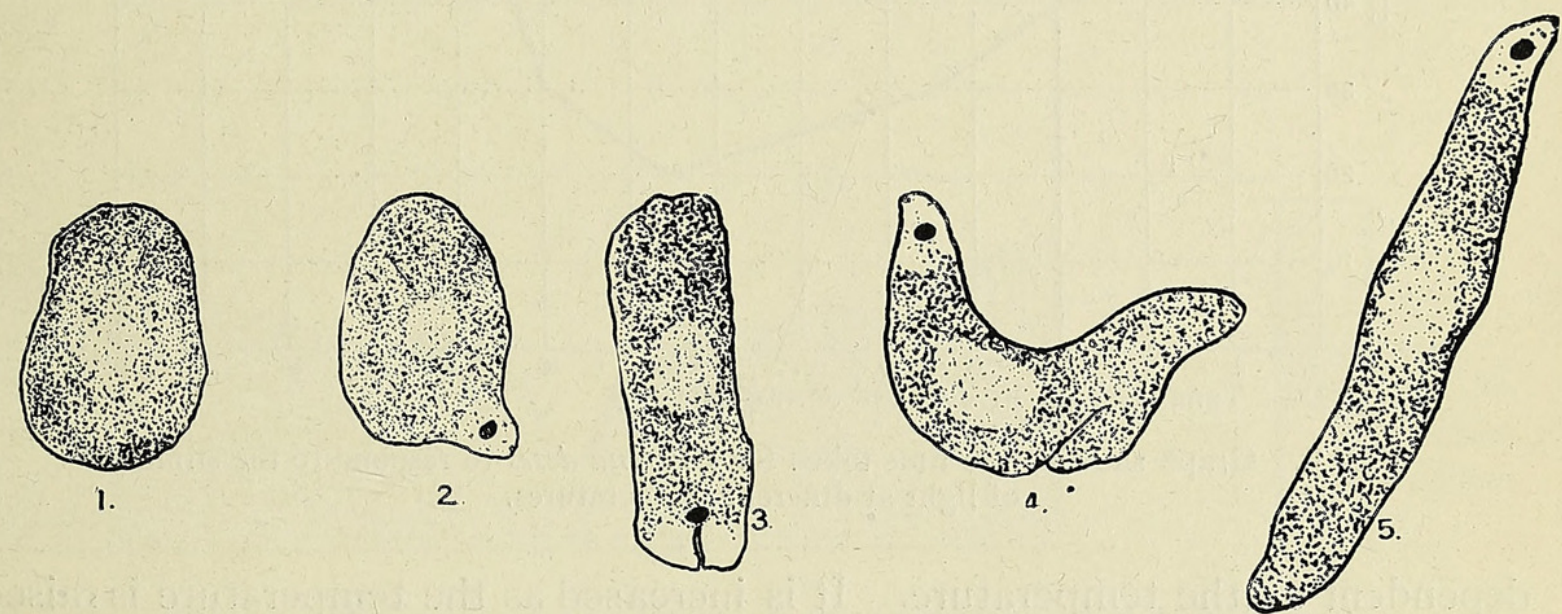

FIG. 7. E. deses. I-5, changes in shape of one individual when warmed from $\mathrm{I} \cdot 5^{\circ} \mathrm{C}$. to $\mathrm{I} 6^{\circ} \mathrm{C}$.

the dark, the Euglenae will not burrow into the mud until the temperature is as high as $2.5^{\circ} \mathrm{C}$. At low temperature the Euglenae appear rounded off, and Fig. 7 shows the changes in appearance when the organism is warmed.

In order to see at what temperature the organism is most active the cultures were kept at different temperatures and covered with a black cloth, and the time taken for complete disappearance was recorded. From a large number of experiments performed, the following results were obtained:

Temperature.
$3^{\circ} \mathrm{C}$.
$6^{\circ} \mathrm{C}$.
$9^{\circ} \mathrm{C}$.
$12^{\circ} \mathrm{C}$.
$15^{\circ} \mathrm{C}$.
$20^{\circ} \mathrm{C}$.
$25^{\circ} \mathrm{C}$.

Time to disappear.

60 minutes (approx.)
$40 \quad "$,
$30 \quad "$,
$25 \quad "$,
$20 \quad "$,
30
I $\frac{\text { I }}{2}$ hours


A graph showing these results is given in Fig. 8 .

$E$. deses is therefore capable of withstanding extremes of temperature for short periods, but is less able to withstand long periods of adverse conditions. The organisms become very sluggish if subjected to temperatures above $25^{\circ} \mathrm{C}$. or below $5^{\circ} \mathrm{C}$, and below $2.5^{\circ} \mathrm{C}$. no response to stimuli has been observed. The rate at which the organism responds to stimuli is

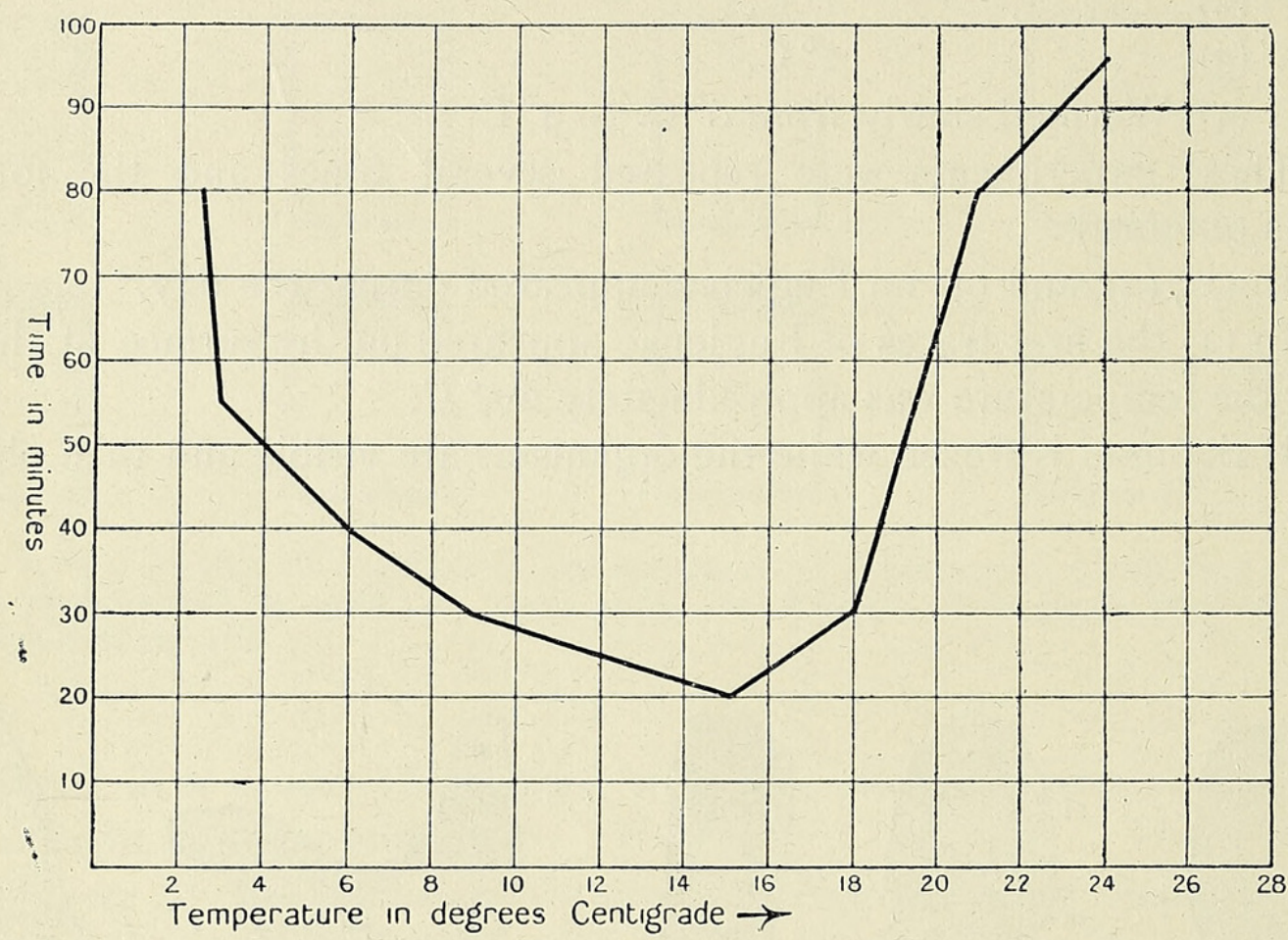

FIG. 8. Graph showing the time taken for Euglena deses to respond to the stimulus of light at different temperatures.

dependent on the temperature. It is increased as the temperature is raised, but above $5^{\circ} \mathrm{C}$. its activities grow less.

\section{DEPTH TO WHICH E. DESES BURROWS IN MUD.}

Experiments were performed with a view to finding the depth the Euglenae burrow in the mud in response to stimuli. By means of a Gillette razor-blade the surface mud was scraped off in several dishes to a depth of $\frac{1}{8}$ in., $\frac{1}{4}$ in., and $\frac{1}{2}$ in. respectively. The time chosen was after the cultures had been placed in the dark, i.e. when the Euglenae had burrowed into the mud.

As a result it was found that in the $\frac{1}{8}$ inch experiment a large number of Euglenae reappeared when placed in the light, in the $\frac{1}{4}$ inch a few, and in the $\frac{1}{2}$ inch none at all.

Therefore one would conclude that the majority of Euglenae do not burrow deeper than $\frac{1}{4}$ inch. The experiment was repeated by inserting a strip of Bolton silk, mounted on a frame at an angle of $45^{\circ}$, in the mud. The organisms burrowing down became entangled in the meshes, and by 
measuring the distance down the slope over which the organisms are to be found one is able to calculate the greatest distance to which they burrow.

As a result it was found that the greatest depth was about $\frac{1}{2}$ inch, while the majority were found at about $\frac{1}{8}$ inch. This agrees with the results obtained in the previous experiment, and also with that obtained by Laurie for Amphidinium, which he says burrows to a depth of about $\frac{1}{8}$ inch (6).

\section{Climatic Conditions.}

(I) Rain. Several visits paid to the Avon during wet weather show that $E$. deses does not appear on the actual surface of the mud during rain. If, however, one examines the sides of the small drainage channels which
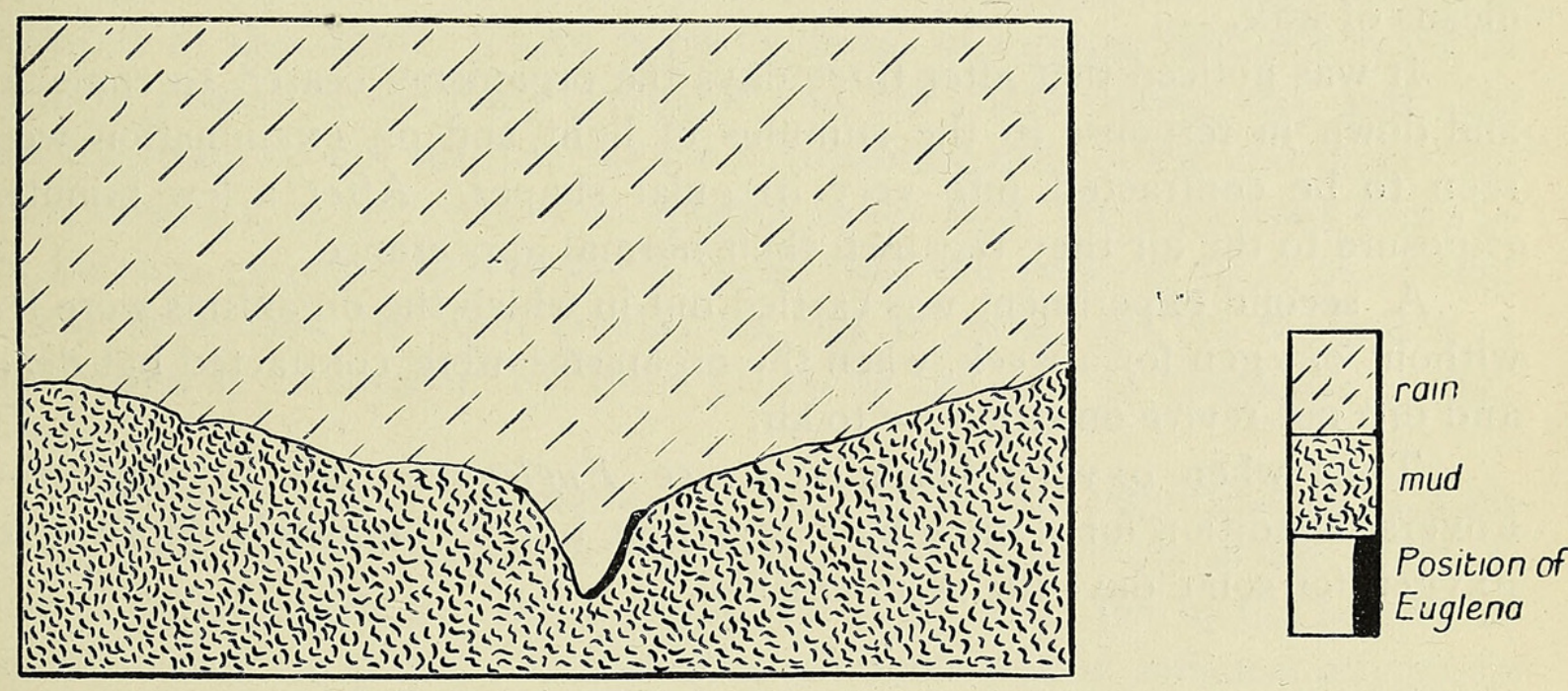

FIG. 9. Showing position taken up by Euglenae on the mud during rain.

run through the mud at right angles to the river, one can see a large number of Euglenae clustered here to obtain shelter from the rain, and it is a noteworthy fact that they occur in far greater numbers on the side from which the rain is driving and so are almost in complete shelter. A section drawing is shown in Fig. 9.

(2) Drought. The mud at the outer edges of the river bank often becomes very dry when the tide does not cover it for some days, and in order to see the effect of drying on the organism, mud was kept in dishes and left until quite dry and hard.

On examination it was found that all the Euglenae were dead and disorganized.

Other mud was kept until it became very stiff but was still soft enough to receive an impression. With this the Euglenae ceased to respond to the stimulus of light and remained on the surface of the mud. They appeared rounded off and dark green in colour. On subsequent wetting the organisms 
regained their activity and were capable of responding to the light stimulus. In none of the experiments was found any sign of encysted forms.

$E$. deses is therefore able to withstand drying up to a certain point, but as soon as the mud becomes hard and crumbles, the organism is apparently killed.

\section{THE NEED FOR OXYGEN.}

It has been shown that $E$. deses will not live in stagnant water. This is probably owing to the lack of suitable food and partly to the lack of oxygen.

In order to investigate the second factor separately, a dish containing mud and Euglenae was placed under a bell-jar with pyrogallic acid and potash. The bell-jar was sealed to the glass plate on which it stood by means of wax.

It was noticed that after three days the organisms ceased to come up and down in response to the stimulus of light, and on examination were seen to be contracted into very irregular shapes. After a few minutes' exposure to the air they regained their normal appearance.

A second experiment was carried out in which the organisms were left without oxygen for a week, when the organisms were contracted but dead, and did not revive on exposure to air.

Thus when oxygen becomes scarce Euglena is able to resist this adverse condition for a time by contraction, but if completely deprived of oxygen for some days life is impossible.

\section{SUMMARY.}

The behaviour of E. deses living on the banks of the Avon is dependent on certain external factors, namely, light, tidal flow, and temperature changes.

The infuence of light. This influence is a direct one and therefore of great importance. The Euglenae are visible on the mud during day-time, but burrow under the surface during the night, which phenomenon can be brought about by placing the organisms at any time in darkness.

The infuence of tidal flow. The tidal influence shows itself inasmuch as the organism burrows into the mud during the period that it is covered by the tide. If the time of high water is not more than three hours after sunrise the appearance of the organism is delayed, and correspondingly, if the time of high water is not more than four hours before sunset, the reappearance of the Euglena does not take place that day. Further, E. deses possesses a tidal periodicity which causes it to respond to the stimulus for about three days after being removed from the actual tidal influence.

The infuence of temperature changes is not so important as those 
mentioned above, as $E$. deses is active at any temperature between $2.5^{\circ} \mathrm{C}$. and $25^{\circ} \mathrm{C}$. Outside these limits its movements are arrested. By raising the temperature the movements of the organism are accelerated within certain limits, the optimum temperature being about $15^{\circ} \mathrm{C}$.

\section{Conclusion.}

One would conclude from the foregoing experiments that the life of Euglena deses is dependent on a series of movements which the organism performs each day. With regard to the physiological reasons for such movements very little can be said, but it is worthy of note that the two series of movements, namely, those in response to light and those in response to the tide, are different in nature. The influence of light is a direct one, for Euglenae placed in the dark at any time disappear, to reappear when replaced in the light. There is no evidence of any periodic effect, for in cultures placed in the dark overnight and left there during the next day the Euglenae do not reappear at the accustomed time in the morning. As soon, however, as the culture is replaced in the light the organisms come to the surface. From this one would think that the periodic tidal movement is not dependent on light conditions, but is rather due to the shock of the waves, as is thought by Bohn (2) to be the case in Convoluta roscoffensis.

Finally, it is very interesting to observe how the requirements of such an organism as $E$. deses are so well suited to the conditions under which it lives. Being unable to swim freely in water, it cannot live at the bottom of ponds or stagnant pools, or it would be unable to obtain sufficient oxygen to carry on its life processes, and on the other hand it is unable to withstand drought and could not live in mud which is liable to become completely dried in the summer. The periodic tidal flow is therefore an ideal condition, since the organism is kept moist and has also long periods of exposure when it is able to carry on respiration to a greater extent than when covered by water. The tide tends to keep the mud at fairly equable temperatures, and this is of distinct advantage, since the organism is unable to withstand extremes of temperature.

Being thus so well adapted to its mode of life, the organism is able to exist in the vegetative state all the year round, and this may account for the fact that no encysted forms, so common in E. viridis during dry seasons, have as yet been observed here.

In the struggle for existence the organism has evolved a structure which enables it to live in an habitat where few other organisms occur, and so the seasonal dying out of the species, which occurs in ponds when one form of organism supplants another, plays no part here, and the organism is present in immense numbers all the year round. 
I take this opportunity of offering my best thanks to Dr. O. V. Darbishire, under whose direction the work was carried out, and also to Professor Gamble, F.R.S., and Miss E. M. Lee, M.Sc., for valuable help and advice.

Department of Botany, UNIVERSITY OF BRISTOL.

\section{BIBLIOGRAPHY.}

1. ВонN : Sur les mouvements oscillatoires de Convoluta roscoffensis. Comptes rendus des Séances de l'Académie des Sciences, vol. cxxxvii, 1903, pp. 576-8.

2. - : Périodicité vitale des animaux soumis aux oscillations du niveau des hautes mers. Comptes rendus des Séances de l’Académie des Sciences, vol. cxxxix, 1904, pp. 610-11.

3. DANGEARD: Recherches sur les Engléniens, pp. 92-9.

4. -

5. Gamble and Keeble: The Bionomics of Convoluta roscoffensis. Quarterly Journal of Microscopical Science, vol. xlvii, 1903 .

6. LAURIE: On the Bionomics of Amphidinium operculatum. Report of British Association, 1913.

7. WAGER: On the Effect of Gravity upon the Movements of Euglena viridis and other Microorganisms. Phil. Trans. Royal Society, London, vol. cci, pp. 333-90.

8. - : Movements of Aquatic Micro-organisms in Response to External Forces. The Naturalist, June and July, I9I4. 


\section{$2 \mathrm{BHL}$ Biodiversity Heritage Library}

Bracher, Rose. 1919. "Observations on Euglena deses." Annals of botany 33, 93-108. https://doi.org/10.1093/oxfordjournals.aob.a089704.

View This Item Online: https://www.biodiversitylibrary.org/item/235681

DOI: https://doi.org/10.1093/oxfordjournals.aob.a089704

Permalink: https://www.biodiversitylibrary.org/partpdf/320246

\section{Holding Institution}

Smithsonian Libraries

\section{Sponsored by}

Biodiversity Heritage Library

\section{Copyright \& Reuse}

Copyright Status: Not in copyright. The BHL knows of no copyright restrictions on this item.

This document was created from content at the Biodiversity Heritage Library, the world's largest open access digital library for biodiversity literature and archives. Visit BHL at https://www.biodiversitylibrary.org. 